\title{
Socio-Economic Conditions of Tribal Communities in Telangana and Andhra Pradesh - A Review
}

\section{Vijaya Lakshmi* and M Milcah Paul ${ }^{2}$}

${ }^{1}$ Principal Scientist (FRM), AICRP - H.Sc., PG \& RC, Professor Jayashankar Telangana State Agricultural University, Hyderabad ${ }^{2}$ Research Scholar, Department of RMCS, College of Home Science, PJTSAU, Hyderabad

*Corresponding Author: V Vijaya Lakshmi, Principal Scientist (FRM), AICRP - H.Sc., PG \& RC, Professor Jayashankar Telangana State Agricultural University, Hyderabad.

Received: June 18, 2019; Published: July 11, 2019

DOI: $10.31080 /$ ASAG.2019.03.0571

\begin{abstract}
Tribes are one of the diverse groups among the Indian population. They remain disadvantaged mostly as they are considered as the lowest section of the Indian society since the ancient times. The tribes remain disadvantaged due to various factors like geographical and cultural isolation, lack of proper health facilities, inability to satisfy basic needs, lack of control over resources and assets, lack of education and skills, malnutrition, lack of shelter, poor access to water and sanitation, vulnerability to shocks, violence and crime, lack of access to proper infrastructure facilities and technologies and lack of political freedom and voice. All these challenges can make their living a difficult task. Considering these issues, the government is trying to help the tribes through different welfare schemes. This paper tries to analyse the socio-economic status of the tribal communities, the government schemes put forth by the governments of Telangana and Andhra Pradesh for the welfare of tribal communities.
\end{abstract}

Keywords: Socio-Economic Conditions; Welfare Schemes; Tribes; Telangana; Andhra Pradesh

\section{Abbreviations}

SC: Scheduled Caste; ST: Scheduled Tribe; NABARD: National Bank for Agriculture and Rural Development; GCC: Girijan Co-Operative Corporation; MFP: Minor Forest Produce; TRIMCO: Telangana State Tribal Mining Company Limited; TRICOR: Andhra Pradesh Scheduled Tribal Cooperative Finance Corporation Limited; TRICOR: Telangana State Scheduled Tribal Cooperative Finance Corporation Limited; ISB sectors: Industries, Services and Business Sectors; CCDP: Conservation cum Development Plan; PVTGs: Particularly Vulnerable Tribal Groups; SHGs: Self Help Groups; EDP: Entrepreneurial Development Programme; GOI: Government of India; ITDA: Integrated Tribal Development Agency; APSSDC: Andhra Pradesh State Skill Development Corporation; GCC: The Girijan Co-operative Corporation; GVVK: Girijana Vidya Vikas Kendras; RIAD: Remote Interior Area Development.

\section{Introduction}

India is a country which has people of different cultures, religions, traditions, languages, castes and creed. Even in India, every state has its own culture and traditions. Among them, tribal people are one such group that needs to be emphasized. Due to the presence of these tribes, India receives various flavours and real treasures. The tribal peoples of India are also known as "Adivasis", which literally means 'Indigenous People' or 'Original inhabitants of a given region'. Major population of the tribes is found in Chhattisgarh, Orissa, Jharkhand, Madhya Pradesh, North Eastern states and the Andaman and Nicobar Islands [1].

Social development paves the way for economic development. The tribes always face difficulties in their socio-economic development due to various factors like geographical and cultural isolation, lack of proper health facilities, inability to satisfy basic needs, lack of control over resources and assets, lack of education and skills, malnutrition, lack of shelter, poor access to water and sanitation, vulnerability to shocks, violence and crime, lack of access to proper infrastructure facilities and technologies and lack of political freedom and voice. Social sector comprising of sub-sectors like access to education, health and medical care, housing and water supply is very much essential for their economic development.

The criteria followed for specification of a community as a Scheduled Tribe are:

1. Indications of primitive traits,

2. Distinctive Culture, 
3. Geographical isolation,

4. Shyness of contact with the community at large,

5. Backwardness [2]

This criterion is not spelt out in the Constitution but has become well established. It takes into account the definitions in the 1931 Census; the reports of the first Backward Classes Commission (Kalelkar), 1955; the Advisory Committee on Revision of SC/ST lists (Lokur Committee), 1965; the Joint Committee of Parliament on the Scheduled Caste and Scheduled Tribes Orders (Amendment) Bill, 1967 and Chanda Committee Report, 1969 [3].

According to the Census of 2011, the total tribal population of Telangana was $31,77,940$ and Andhra Pradesh was 49,575,771. The numerically dominant tribal groups of Telangana are Lambada/ Banjara, Koya, Gonds, Yerukala/Kurru and Pradhan; whereas Lambada, Yerukula and Yanadi are numerically dominant tribal groups of Andhra Pradesh. This paper tries to focus on the socio-economic conditions of the tribes of Telangana and Andhra Pradesh and the welfare schemes put forth for them by the government.

\section{Objectives of the paper}

1. To analyse the socio-economic status of the tribal communities of Telangana and Andhra Pradesh.

2. To study the government schemes of Telangana and Andhra Pradesh for the welfare of tribal communities.

\section{Methodology}

The literature used to write and analyse the socio-economic conditions of tribes in this paper is collected from various secondary sources like internet, research articles, government reports and websites.

Review of literature

Profile of tribal people in Telangana State

Telangana state is very rich in the variety of cultures that represent all stages of human progress. It has Chenchus, as primitive as those who lived in Stone Age, Gonds, Andhs and Bhils, Koyas and Konda Reddis are still found inclined to indulge in shifting cultivation [4]. Mostly they are found in the highland of Adilabad, Karimnagar, Warangal and Khammam districts and also in Nallamala Plateaux of Mannanur and Farahabad of Mahaboobnagar districts. Yerukala tribe women are indulged in traditional profession of fortune telling. Pradhans in Adilabad district recite mythologies, folk tales and songs of their gods and goddesses at various festivals, ceremonies and fairs for which service they are paid in cash or kind.

\section{Profile of tribal people in Andhra Pradesh State}

The forest-clad mountainous tracts of the East Godavari and Visakhapatnam districts of Andhra Pradesh are the tribal areas of that State, with some twenty tribes speaking either Dravidian or Mundari dialects.
The tribal people of Andhra Pradesh are economically and technologically better equipped than the tribes of other regions. Most of them have youth organizations. The Savara tribes are mainly found in the districts of Visakhapatnam and Odisha. The areas of Savara tribes are full of lofty hills, darting mountain streams and deep gaping valleys, terraced rice fields, etc. The Savara tribe people are remarkable irrigation engineers. They have a primitive sense of village planning, for their houses are aligned in parallel rows which reflect orderliness. The Gadaba tribal people are distributed in the Jeypore, Malkangiri, Koraput and Pattangi taluks. They are like the Savaras, farmers, but hunting and fishing make additional contributions to their food supply. The Gadaba women are good at weaving bark fiber cloth on miniature looms of their own manufacture and the woven fabric is dyed by them with various vegetable dyes. In fact, no Gadaba girl is considered qualified for marriage until she has acquired the requisite skill on the loom. Khonds are distributed both in Orissa and the Visakhapatnam and are one of the largest of the Dravidian-speaking tribes. The Koya tribe is divided into several occupational tribes such as blacksmiths, carpenters, brass workers and basket-makers. During certain lean seasons of the year, food is so scarce that whole families, including children, live on tubers, tamarind seeds and palm juice. The Konda Reddis Tribes are the Telugu speaking tribal people. They share the hilly region with the Koya tribe.

Socio-economic status of the tribal communities of Telangana and Andhra Pradesh

A study results on the socio-economic development of primitive tribes in Adilabad district of Telangana showed that majority of the respondents of the study area were illiterates, adopted nuclear family system and had own houses. Majority of the respondents were farmers, followed by agricultural labourers. As they had no skills in modern agricultural practices, they practised mono cropping pattern. The respondents acquired the modern inputs and financial assistance from Integrated Tribal Development Agency. Majority (87\%) earned income less than 1500 rupees per month and they spend the money mostly on food. The results showed that there is a significant relationship between the government policies and schemes and standard of living of the tribals [5].

A case study on the Socio-Economic conditions of Scheduled Tribes in selected villages in Adilabad District of Telangana State revealed that the literacy rate in the study area is 72 per cent. The Lambada community recorded highest literacy rate, whereas the Kolam community recorded the lowest. Regarding the income levels, the Lambada community recorded the highest and the Kolam community recorded the lowest. Among all the five sub-caste communities in the study area, the Lambada community was very well developed. The recommendations given in the study were to provide more welfare schemes and employment opportunities to improve the well-being of the tribal communities [6]. 
The results of a comparative analysis of the tribal diversity in Andhra Pradesh and Telangana districts depicted that Warangal district of Telangana was dominated by Lambdas (46\%) and Vizag district of Andhra Pradesh was dominated with Valmikis (37\%). Educational status was much better in Vizag than in Warangal. In terms of child immunization, both districts have shown almost same statistics. Ninety four (94) per cent of the respondents in Visakhapatnam district were seasonal wage earners, whereas in Warangal district, 82 per cent were seasonal wage earners. The approximate monthly consumption expenditure on food items is more in Warangal than in Vizag. In terms of land holdings, majority of them hold very small lands which are ancestral in nature. Non-institutional indebtedness is high in Warangal than in Vizag. In both areas, people were aware of government programmes, and the percentage of people who availed these programmes increased drastically from 2012 [7].

A study aimed to find out the socio-economic status of scheduled tribes in Vizanagaram District of Andhra Pradesh state found that majority of the sample households were male headed and worked as famers and agricultural labourers. The income range of famers was Rs. 6000 to Rs. 10000 rupees per annum, and labourers earned lesser than that. There was a decline in the sex ratio in this community, and families had a preference for son. As they had no other sources of income, they tried to take loans and the institutions took advantage of this and charged higher interest rates ( 3 per cent). The researchers recommended that, government should take measures to promote the financial stability among the schedule tribes by offering better banking services and transfer of technology [8].

The socio-economic status of the scheduled tribes in Visakhapatnam district of Andhra Pradesh was studied. In the sample population, majority of the households belonged to Konda Dora and Nooka Dora tribes and more than 70 per cent were illiterate. Cultivation was the primary occupation for majority and the total family income was less than Rs. 10,000 per annum. Food expenditure lied top on the annual expenditure pattern, followed by expenditure on payment of interests on loans and on health concerns. Majority of the sampled households lacked durable household assets. Around 37 per cent of the land-owning sample did not have ownership rights. More than 60 per cent fulfilled their credit needs from private money lenders. Therefore, there is a need to put more attention on educating the scheduled tribes, which can motivate them for their future life [9].

A study on socio-economic and health conditions of Yandi tribes and tribes inhabiting in jungles in North coastal districts of Andhra Pradesh found that, though there are a number of initiatives taken up for improving the living conditions of the tribals, the progress is not up to the mark. The reasons for this is that, forests are depleting at faster rate and are in no way sustaining food requirements of forest dwellers through their traditional means of hunting and gathering. Mostly, they are dependent on agriculture, either as cultivators or agriculture labourers. They are malnourished, poor, and largely illiterate and rank miserably low in all sorts of health indicators despite their wealth of traditional knowledge of keeping healthy [10].

Forests play a vital role in the economic development of the forest dwelling tribes of Andhra Pradesh as they provide them with food in the form of tubers, roots, leaves, fruits, flesh of animals and birds and cures illnesses by supplying medicinal herbs. Skins, hides, horns of wild animals and minor forest produce are exploited for commercial purposes. But, this agro-forest based economy is subject to the behaviour of nature. The rocky terrain, infertile soil, freak nature, extreme seasonal conditions, lack of perennial sources of water, predatory birds and animals and the parasitic hold of money lenders and plains sowcars force them to live in perpetual poverty [11].

Welfare schemes by the Government of Telangana for the tribal communities (Source: Tribal Welfare Department, Government of Telangana)

For the benefit of tribal population, Telangana government has taken up serious action to implement various welfare schemes as given below:

\section{Education schemes}

- $\quad$ Funding for maintenance of educational institutions, hostels, integrated hostels, ashram schools, post -matric hostels, tribal welfare primary schools, teacher education colleges, student coaching programmes for competitive examinations

- $\quad$ Tuition Fee and Post-Matric Scholarships

- $\quad$ Pre-Matric Scholarships

- Monetary Support to study in Hyderabad Public Schools

- Upgrading Tribal Welfare Ashram Schools into Schools of Excellence

- $\quad$ Setting up Residential Schools for Tribals

- $\quad$ Setting up Residential Schools for Tribal Girls

- Upgradation of Residential Schools into Junior Colleges of Excellence

Other developmental Schemes

- Kalyana Lakshmi: With a view to alleviate financial distress in the families of Scheduled Tribes, "Kalyana Lakshmi" scheme under which financial assistance of Rs.51,000 shall be paid to every ST unmarried girl of 18 years and above or at the time of marriage parental income shall not exceed 2 lakhs per annum.

- Komaram Bheem memorial: In memory of the brave Gond tribal leader who fought against the Nizams under the slogan “Jal, Jameen, Jungal” the Government sanctioned construction of Komram Bheem Smriti Chihanam and also develop- 
ment of Jodeghat village as Tribal Cultural Hub and Tourism Center, at an outlay of 50 Crores.

- Constructions of Roads under NABARD Programme: The objective of the scheme is to provide road connectivity in tribal areas with financial assistance from NABARD.

- Construction of Go-downs and Storage Points: This scheme is intended to provide Go-downs /Storage Points for supply of daily food requirements to people living in tribal areas.

- Works under Medaram Jathara: Under this scheme, all infrastructural works required for the conduct of biggest Tribal Jathara "Sammakka Saralamma Jathara" being held once in two years at Medaram village in Warangal District will be taken up.

- Construction of buildings for Integrated Residential Schools: The objective of this scheme is to provide additional infrastructure for Ashram High School and Residential Schools in tribal areas with financial assistance from NABARD, Trench XVIII and XIX.

\section{Economic support schemes}

Girijan Co-operative Corporation (GCC) undertakes procurement of minor forest produce (MFP) and agriculture produce from tribals at remunerative prices, undertakes public distribution in remote tribal areas, provides seasonal agricultural credit to ST farmers.

Telangana State Tribal Mining Company Limited (TRIMCO) was established to take up mining activities with active participation of tribal mining Co-operative Societies, as there is availability of mines and minerals in Telangana State.

Consequent on State Reorganization Act - 2014, the Andhra Pradesh Scheduled Tribal Cooperative Finance Corporation Limited (TRICOR) is bifurcated into two separate operational units. Thus, Andhra Pradesh Scheduled Tribal Cooperative Finance Corporation Limited (TRICOR) for residuary state of Andhra Pradesh and Telangana State Scheduled Tribal Cooperative Finance Corporation (TRICOR) for newly formed state of Telangana.

The major activities of TRICOR are

To provide financial assistance to STs for Economic Support in the areas of:

- Agriculture

- Fisheries

- Animal Husbandry

- Minor Irrigation

- ISB sectors

- $\quad$ Self-Employment
Impart training

- $\quad$ Skill up gradation for wage employment/formal employment/self - employment

- $\quad$ Capacity Building

Special programme for development of PVTGs through Conservation-Cum Development Plan (CCDP).

Conservation cum Development Plan (CCDP) was introduced during XI Five Year Plan period effective from 01/04/2008. The programme aimed at planning socio - economic development of Particularly Vulnerable Tribal Groups (PVTGs) in a holistic manner by adopting habitat development approach and intervening in all spheres of their social and economic life to enhance the quality of life so that a visible impact is made. The major activities of the programme are as follows:

- $\quad$ Construction of Multi-purpose building

- Construction of Internal roads/drains

- Providing Corpus fund to SHG for livelihood interventions

- Any other felt need of the PVTG community for which there is no source from any other government programme/ scheme.

\section{Skill development programmes}

Separate Sub Mission was constituted for STs for implementation of Skill Development initiatives in the Scheduled Areas. Multiple Skill Development activities have been initiated to provide employment opportunities to the unemployed tribal youth on its own and through training partners from Government training institutes/Private training institutes for the benefit of tribal unemployed youth. The Strategy of implementation of this programme is:

- Organizing orientation programmes in the name of Bhavitha for creating awareness among the tribal youth.

- Imparting placement linked training to ST youth for up gradation of their skills.

- $\quad$ Organising Direct Placement drives in tribal areas.

- Organizing Self Employment/Entrepreneurial Development Programme (EDP) [12].

Welfare schemes by the Government of Andhra Pradesh for the tribal communities (Source: Tribal Welfare Department, Government of Andhra Pradesh)

Economic support schemes and schemes under tribal area sub plan

Under this, financial assistance is given to ST families below poverty line for taking up economic support activities. The action plan for these programs is approved by Andhra Pradesh Scheduled 
Tribes Cooperative Finance Corporation Limited (TRICOR), Hyderabad. TRICOR reviews the implementation from time to time.

\section{Conservation-cum-Development Plans (CCDP) of PVTGs}

Government of India (GOI) has approved Conservation Cum Development Plan for the development of PVTGs for a period of five (5) years starting from 2012-13. GOI have released Rs.33.20 Cr. during 2014-15 and 2015-16. Under this, schemes such as Backyard Poultry and Kitchen gardens for food security, Corpus funds for health emergencies, and support to Voluntary Organizations for involving in livelihood activities and improving health and nutrition status were taken up.

During 2016-17, proposals were submitted to GOI for sanction of Rs.40.64 Cr. for providing micro projects that create food security, habitation development activities for improving health, hygiene and nutrition conditions, etc. GOI has released Rs.13.20 crores so far.

\section{Development of Coffee plantations in ITDA, Paderu area}

The Government have approved a comprehensive Development of Coffee Project in Integrated Tribal Development Agency (ITDA), in Paderu area at a total cost of Rs.526.16 Cr. for implementation over a period of ten years from 2015-16 to 2024-25. The project work comprises of: (1) Expansion of Coffee Plantations; (2) Coffee Consolidation/ Rejuvenation; (3) Organic Certification; (4) Promotion of Wet pulping through supply of Baby pulpers; and (5) Marketing support.

\section{Skill Upgradation of formal and self-employment}

Government of Andhra Pradesh is keen in development of Skills of ST unemployed youth by imparting training and providing placements. For this purpose, Government have sanctioned a Sub Mission exclusively for STs for taking up skill upgradation training and placement in the Scheduled Areas, so that there will be a sustainable and formal self-employment. Youth Training Centres were constructed aimed to create aspirational training infrastructure in the tribal areas. During 2015-16 Andhra Pradesh State Skill Development Corporation (APSSDC) implemented training to 2700 (ST) Youth in various Trades through their Training partners across the State.

\section{The Girijan Co-operative corporation (GCC)}

It is a public sector undertaking of government of Andhra Pradesh established in the year 1956 with a single mission, which is the socio-economic upliftment of Tribals. The forests in this state play a significant role in sustaining the livelihood of these people, especially the sale of forest produce (non-timber forest products), since agricultural activity by itself is not sufficient for sustenance, or as a source of livelihood. GCC was instituted with the sole purpose to protect them from exploitative middlemen, petty traders and establish a mutually beneficial relationship between them and the rest of the world.

\section{Education schemes and programmes Girijana Vidya Vikas Kendras (GVVK)}

Providing access to education by teachers and later sent for teacher training at government cost. This measure introduced in 1986 brought an enrolment explosion in the areas of Tribals; out of 4317 GVVKs, 351 GVVKs are upgraded to primary schools in 2001-02. Government of Andhra Pradesh has sanctioned permanent buildings for all these upgraded schools under DPEP during 2003-04. Presently, these GVVKs are called Tribal Welfare Primary Schools.

\section{Ashram schools}

The Ashram Schools were opened in 1974 to provide both school and hostel under the same roof and these were exclusively for Scheduled Tribes. The Ashram Schools are established in all districts of Andhra Pradesh state. Presently, 599 Ashram Schools are functioning in the tribal concentrated areas and have been centres of awareness, social renaissance and qualitative academic progress. Each of the Integrated Welfare Hostel Complexes will provide accommodation for 400 boarders belonging to scheduled castes, Scheduled Tribes and backward class. For each complex, buildings and other amenities are being provided adequately.

\section{Hostel buildings for degree colleges}

The scheme is intended to provide hostel buildings for PostMetric scheduled tribe students studying in eight degree colleges. Each degree college will have one boys' hostel and one girls' hostel. Children admitted in the hostels will receive maintenance charges of Rs. 525 per month under Post-Metric Scholarships.

\section{Construction of high schools}

The scheme is intended to provide additional accommodation to high schools especially tribal welfare girls' in Ashram high schools located in the RIAD area.

\section{Buildings for educational institutions}

The objective of the scheme is construction of buildings (new/ additional accommodation) for Integrated Hostels, Post-Metric Hostels and Ashram Schools which are in private accommodation. The funding is shared by state and central government on 50:50 bases. 


\section{Apart from these}

- $\quad$ Funding for maintenance of educational institutions and hostels, integrated hostels, ashram schools, post-matric hostels, tribal welfare primary schools, teacher education colleges, student coaching programmes for competitive examinations

- Gurukulam schools

- Monetary Support to study in Hyderabad Public Schools

- Tuition Fee and Post-Matric Scholarships

- $\quad$ Pre-Matric Scholarships

- Upgrading Tribal Welfare Ashram Schools into Schools of Excellence

- $\quad$ Setting up Residential Schools for Tribals

- $\quad$ Setting up Residential Schools for Tribal Girls

- Upgradations of Residential Schools into Junior Colleges of Excellence are also put forth, which are similar to the ones put forth by Telangana Government [13].

\section{Conclusion}

Social and economic justice, equality of status and opportunities, assurance of the individual's dignity are ensured by the Constitution of India for all the citizens among other things. The constitution of India is enriched with several provisions for schedule castes and schedule tribes to safeguard and promote their cultural, social, educational, and economic interests to bring them in the mainstream of the nation. Both Telangana and Andhra Pradesh governments are working hard towards the enrichment of tribal lives.

\section{Bibliography}

1. Kumbhkar K. The Tribal States of India. Walk through India (2010).

2. Change in Criteria for inclusion in ST List. Ministry of Tribal Affairs, Government of India (2017).

3. Ethnographic profile of major tribes of Andhra Pradesh. Government of Andhra Pradesh, 2016-17.

4. Lankati Mahesh L., et al. "Employment Generation of Tribal Farmers of Adilabad and their relationship with Profile Characteristics". International Journal of Current Microbiology and Applied Sciences 6.7 (2017): 593-599.

5. Lal S and Devanna S. "Socio-economic development of primitive tribes: an empirical study in Adilabad district". International Journal of Information Research and Review 3.10 (2016): 2951-2956.
6. Naik BR. "A Socio-Economic Condition of Scheduled Tribes: A Case Study of Selected Villages in Adilabad District, Telangana State." Indian journal of Applied Research 6.7 (2016): 42-45.

7. Lalitha P. "Tribal Diversity in Andhra Pradesh and Telangana: A Comparative Analysis". American International Journal of Research in Humanities, Arts and Social Sciences 7.2 (2014): 131-139.

8. Kumar PR., et al. "Socio-economic status of schedule tribes in Andhra Pradesh". International Journal of Development Research 3.11 (2013): 136-140.

9. Rao PD. "Socio-economic Status of Scheduled Tribes". MERC Global's International Journal of Management 1.1 (2013): 3650 .

10. Babu KS. "Socio-economic and health conditions of some major tribes in Andhra Pradesh". Social Work Chronicle 1.2 (2012).

11. Profile of scheduled tribes in Andhra Pradesh. Shodhganga. Chapter 2 (2005).

12. Developmental schemes. Tribal Welfare Department, Government of Telangana.

13. Ravindera D. "Tribal development programmes in Andhra Pradesh - an overview". The dawn journal 3.1 (2014): 817837.

Volume 3 Issue 8 August 2019 (C) All rights are reserved by $\mathrm{V}$ Vijaya Lakshmi and $M$ Milcah Paul. 